\title{
The Correlation between Blood Pressure and BMI in Students of Shahrekord University of Medical Sciences in 2013-14
}

\author{
Research Article
}

\section{Elham Rafiee ${ }^{1}$, Mansoor Khaledi ${ }^{2}$, Mostafa Madmoli ${ }^{3}$, Mehdi Zafari ${ }^{4}$, Masoud Lotfizadeh ${ }^{5 *}$}

1. Masters of Public Health, Shahrekord University of Medical Sciences, Shahrekord, Iran.

2. MS.c. in Medical Microbiology, Department of Microbiology and Immunology,

Shahrekord University of Medical Sciences, Shahrekord, Iran.

3. Emergency Medical Technician, Dezful University of Medical Sciences, Dezful, Iran.

4. Student Research Committee, Shahrekord University of Medical Sciences, Shahrekord, Iran.

5. Associate professor, Social Determinants of Health Research Center,

Shahrekord University of Medical Sciences, Shahrekord, Iran.

\begin{abstract}
Background: Hypertension is one of the most common disorders and is a major public health problem that causes $20 \%$ to $50 \%$ of world mortality. On the other hand, obesity is also a risk factor for type 2 diabetes, cancer, cardiovascular disease, osteoarthritis and has a major share in health costs. Therefore, the relationship between body mass index and blood pressure has been considered. By this study, in general, about these indicators in the age group of under 30 years, useful information can be found. Methods: In order to collect information, a questionnaire was prepared and a random sampling was completed for a number of students from Shahrekord University of Medical Sciences. The data were analyzed using spss version 22. Results: By analyzing the results, it was found that systolic and diastolic blood pressures of both hands had a direct and significant relationship with age, so that by increasing the age, there is an increasing in hypertension $(\mathrm{p} \leq 0.001)$. Systolic blood pressure also showed a significant relationship with gender, and it was found that in men it is more than women. Finally, in examining the relationship between BMI and blood pressure, the results show that there is a positive and significant relationship between these two parameters, so that the increase in BMI also increases the systolic and diastolic blood pressure $(\mathrm{p}=0.0001)$. Conclusion: Blood pressure in students has a direct and significant correlation with age, sex, and body mass index.
\end{abstract}

Keywords: High Blood Pressure, Body Mass Index, Obesity, Students.

\section{Background}

Obesity is a major public health problem associated with chronic diseases such as cardiovascular disease, type 2 diabetes, cancers and depression (1). Overweight and obesity are rising in the world. In 2005 , the total number of overweight adults in the world was 937 million and the number of obese people was 396 million, which has doubled in comparison with the past 20 years, and it is expected that by 2030 , it will increase to 1 billion and 573 million people (2). In Iran, in 2005 , the prevalence of overweight and obesity was $42.8 \%$ in men and $57 \%$ in women, and is projected to reach $54 \%$ and $74 \%$ in 2015 , respectively (3). High blood pressure is a common, asymptomatic, yet easily

\section{*Corresponding Author:}

Masoud Lotfizadeh,

Associate Professor,

Social Determinants of Health Research Center,

Shahrekord University of Medical Sciences,

Shahrekord, Iran

Email id: masoudlotfi235@gmail.com identifiable and curable condition. Hypertension due to its high prevalence and associated with cardiovascular disease is a health problem in industrialized and developing countries. In industrialized countries, $25 \%$ of adults and $60 \%$ of people over 60 have high blood pressure (4). In the Middle East, high blood pressure is one of the most prevalent non-communicable diseases (5). Studies in Iran also show a high prevalence of hypertension (6). This research and future research in this field can significantly reduce the cost of health and promote the health of the community. Therefore, this study has been conducted to determine the prevalence of overweight and obesity, high pre-hypertension and high blood pressure in students of Shahrekord University of Medical Sciences. To obtain general information about the physical and health status of the students, and considering that the measurement of blood pressure and BMI in this age group is not common, with this sampling, we can generally find out about the importance of these two indicators in a group under the age of 30 years. 


\section{Methods}

This descriptive-analytic study was conducted among students of different fields of Shahrekord University of Medical Sciences in 2013. In this research, 400 students from all disciplines and sections from the age range of 18 to 36 years old were selected through multi-stage random sampling, which included all the colleges. The required information was measured using a researcher-made questionnaire. In addition to the demographic characteristics, characteristics related to the history of the person's illness and lifestyle, including dietary habits and physical activity, were evaluated, in order to measure the weight of the students examined, from a standard bearing weight were taken from the provincial health center. We used a tape measure similar to those used in health centers to measure their height. Data from supplementary questionnaires was analyzed using SPSS software, the significance level in this study is 0.05 .

Out of 400 questionnaires that were distributed among students, 371 questionnaires were used to complete the required information. One of the strengths and distinctions of this study was research with other studies on the relationship between blood pressure and mass index the body is that in this study, while measuring the blood pressure in each person, the comparison between the left and right hand blood pressure is also done, which provides further investigation for researchers.

This study shows that the average systolic and diastolic blood pressure among students is in the normal range, and high blood pressure (as defined) has not been observed among students, but pre-blood pressure has been observed in $3.5 \%$ of students. Of the studied students, the majority (71.4\%) had normal BMI, 7.5\% had overweight and $0.5 \%$ had first grade obesity.

In this study, it was found that systolic and diastolic blood pressure has a direct and significant relationship with age and increases with age. The results also show that there is a significant positive relationship between weight gain and hypertension.

Based on the results of this study, although the prevalence of high pre-hypertension, high blood pressure, overweight and obesity among Shahrekord University of medical sciences students compared to similar studies among other university students and similar studies in lower and higher age groups, But correlation between blood pressure and weight and also significant relationship between these factors and other factors such as age and sex are similar to other studies and there is a positive and significant relationship.

\section{Results}

In this study, among 371 students (229 males and 142 female) students from different fields of Shahrekord University of Medical Sciences, the mean age of the subjects was $21.6 \pm 2.35(21.57 \pm 2.43$ girls and $21.62 \pm$ 2.22 boys) and the age range was $18 \mathrm{Up}$ to 36 years old.
The highest mean age of the study was 20 years old with $25.9 \%, 21$ years old with $23.5 \%$ and 22 years old with $19.9 \%$, respectively. The age group of $30-36$ years had a total of $1.2 \%$ with the lowest share. Also, medical students with $19.9 \%$ (74 people) had the highest contribution in this study, after which the students of the field $13.5 \%$ (50 people), laboratory sciences with $11.9 \%$ (44 people) and public health with $10.8 \%$ (40 people) had a major contribution in this study, with the lowest proportion of students in different fields with 3.5\% (13 people) and medical emergencies with $2.7 \%$ (10 people). Most of the students studied were undergraduate students with $73.6 \%$ (273 people), and most of the students studied were graduates of 2 years. The findings also show that $88.9 \%$ (330) of the studied students were native to Chaharmahal and Bakhtiari province and the rest were non-native students. It should be noted that $88.9 \%$ (330) students living in the student dormitory and $11.1 \%$ (44 people) lived in their own homes and with the family; none of the students studied were living in a rented home. Table 1 shows the variables studied in the whole population generally, separated by sex. One of the subjects in the study, $20.5 \%$ ( 76 people) had a BMI of less than $18.5,71.4 \%$ (265 people) had a BMI of 18.5 to 25.5 and $7.5 \%$ (28 people), BMI 25 to 30 (overweight) and $0.5 \%$ (2 people) have a BMI greater than 30 (grade 1 obesity).

Among the subjects in the study of right-systolic blood pressure, the information indicates that 3.5\% (13 people) had systolic hypertension and the rest of the subjects had 96\% (358 people) normal systolic blood pressure. In the study of left ventricular systolic blood pressure, the findings are approximately the same as the right hand side, and the number of people with hypertension was $3.8 \%$ (14 cases), and the rest had normal systolic blood pressure $(96.2 \%)$.

The results of studies on right systolic blood pressure in students indicate that $3.5 \%$ (13 cases) had diastolic hypertension and the rest had normal diastolic blood pressure. Findings from the review of the diastolic blood pressure of the left hand are consistent with the findings of the right hand.

In examining the relationship between blood pressure and various variables, it is important to note that although two blood pressure measurements from both hands are measured, the basis for the conclusion and used in the study is based on the second one because the first turn is to reduce stress and Making a person's readiness to measure second blood pressure and more accurate results from second-line blood pressure.

The systolic and diastolic blood pressure of both hands has a direct and significant relationship with age, and by increasing the age the hypertension increases too $(p \leq 0.001)$. The mean right ventricular systolic pressure in female students is 97.38 and in male students is 113.24. According to the information obtained, rightsided systolic blood pressure is higher in male subjects, 
and this relationship is significant $(\mathrm{p} \leq 0.01)$.

The mean left-sided ventricular systolic pressure in female students is 96.10 and in male students is 113.80 . According to the information obtained, systolic blood pressure is higher in single subjects ( $\mathrm{p}>0.05)$.

The mean right-sided diastolic blood pressure in female students is 60.68 and in male students is 73.60. The right diastolic blood pressure in male students is higher but this relationship is not significant ( $p>0.05$ ).

The mean left-sided ventricular diastolic blood pressure was 60.52 in female students and 73.60 in male students, which is directly related to male sex, but this relationship is not significant $(p>0.05)$. Overall, the findings of the study indicate that all pre-hypertensive patients, who were $3.5 \%$ (13 cases), were male students, this condition was in the left and right hand systolic and pre-hypertensive hypertension, And the left hand is true and shows a meaningful relationship $(p=0.001)$.

The mean right-sided ventricular systolic pressure in single students is 103.93 and in married students is 99.2. According to the information obtained, systolic blood pressure is higher in single subjects, but this relationship is not significant ( $\mathrm{p}>0.05)$.

The mean left-sided ventricular systolic pressure in single students is 103.56 and in married students is 96.92 . According to the information obtained, systolic blood pressure is higher in single subjects, but this relationship is not statistically significant ( $\mathrm{p}>0.05)$.

The mean right-sided diastolic blood pressure in single students is 65.75 and in married students is 64.47 . The right diastolic blood pressure in single students is higher $(\mathrm{p}=0.035)$.

The mean left ventricular diastolic blood pressure in single students is 65.77 and in married students is 63.42. According to these findings, left hand diastolic blood pressure is higher in single students but this relationship is not statistically significant $(\mathrm{p}>0.05)$.

There was no significant difference in mean blood pressure in healthy students and students with a history of specific disease (except for blood pressure).

In the study of the history of hypertension in the students' family it was found that there was no significant relationship between high blood pressure in students and familial history of hypertension. Only the right-sided ventricular hypertension had a significant relationship with familial history of hypertension $(p=0.02)$.

The average blood pressure in students with a history of myocardial infarction in their families is not significant.

Right-systolic hypertension in smokers was 113.82 and in non-smokers 102.99 and right hand diastolic blood pressure in smokers and non-smokers was 73.24 and 65.27 , respectively.

Left systolic blood pressure in smokers and nonsmokers was 112.06 and 102.48, respectively, and left hand diastolic blood pressure in smokers and nonsmokers was 72.35 and 65.21, respectively.

These findings indicate that the mean systolic and diastolic blood pressure in smokers is higher than nonsmokers, but this relationship is not statistically significant.

The average right-sided systolic and diastolic blood pressure in students who regularly exercise over the week is 108. 33 and 69.75, respectively, and in students who do not exercise regularly during the week, they are 102.56 and 65.00 respectively. The average left -sided diastolic and systolic blood pressure in students who exercise regularly during the week is 108.58 and 96.08 respectively, and in students who do not exercise regularly during the week, 101.81 and 64.87 , but the relationship between these findings is not statistically significant.

The results of this study indicate that there is no significant relationship between salt intake and sugar and blood pressure in students. Among them, only rightsided diastolic blood pressure with direct sugar consumption showed direct and significant relationship $(\mathrm{p}=0.016)$.

In examining the relationship between sex and the amount of exercise during the week, it was found that the amount of exercise and regular activity was significantly higher in boys than in girls $(p=0.001)$, so that $6.6 \%$ of girls exercised regularly during the week While $27.5 \%$ of boys have regular exercise during the week. The rate of smoking was significantly higher among boys than girls, and the relationship between

Table 1: Some variables studied in general and by sex

\begin{tabular}{|r|r|r|r|r|r|r|}
\hline & \multicolumn{2}{|l|}{ Female } & \multicolumn{2}{l|}{ Male } & \multicolumn{2}{l|}{ total } \\
\hline & Mean & $\begin{array}{r}\text { Standard } \\
\text { deviation }\end{array}$ & Mean & $\begin{array}{r}\text { Standard } \\
\text { deviation }\end{array}$ & Mean & $\begin{array}{r}\text { Standard } \\
\text { deviation }\end{array}$ \\
\hline Age & 21.57 & 2.43 & 21.6 & 2.22 & 21.6 & 2.35 \\
\hline Systolic blood pressure & 96.10 & 12.56 & 113.80 & 8.89 & 102.88 & 14.19 \\
\hline Diastolic blood pressure & 60.52 & 9.24 & 73.59 & 8.09 & 65.53 & 10.86 \\
\hline Body mass index (BMI) & 20.79 & 2.86 & 21.07 & 2.81 & 20.90 & 2.84 \\
\hline
\end{tabular}


smoking and sex was significant, only $0.4 \%$ of smokers were girls, while $11.3 \%$ of boys smoked $(p=0.001)$.

In examining the relationship between body mass index and blood pressure, the results show that there is a positive and significant relationship between these two parameters, so that with the increase in BMI, the systolic and diastolic blood pressure also increases $(\mathrm{p}=$ $0.001)$.

\section{Discussion}

In this study, the prevalence of overweight and obesity among students of Shahrekord University of Medical Sciences, who were between the ages of 18 and 36 , was $7.5 \%$ and $0.5 \%$, respectively. In a similar study by Rahmati among 3931 students of Tehran University with age range from 17 to 48 years old, the prevalence of overweight and obesity was $13.5 \%$ and $3.2 \%$ respectively (2). In another study by Salem among 694 students of Rafsanjan University of Medical Sciences, the prevalence of overweight and obesity was $10.7 \%$ and $1.4 \%$ respectively (1), another study by Mortazavi and Shahraki Poor students in Zahedan University of Medical Sciences have reported that the prevalence of overweight and obesity in this study was $12.9 \%$ and $1.3 \%$ (9). Comparing the present study with the three studies, all of which, like our study among the students, showed that the prevalence of overweight and obesity was lower in this study. Two other examples of studies in this regard, but in different target groups, are one study by Khosravi et al., Entitled "Healthy Heart Project" in Isfahan, Najaf Abad and Arak, among 12514 women and men of average age 38 Year and the prevalence of overweight and obesity grade one is $33 \%$ and $12.3 \%$, respectively (6), and another is a study by Khaji et al. In adolescents in the fifth grade of elementary school in Tehran and the prevalence of overweight and Obesity among these adolescents was reported to be $7.7 \%$ and $6.3 \%$ respectively (8). As it can be seen, the present study compared the prevalence of overweight and obesity among students of Shahrekord University of Medical Sciences compared with the studies. These changes in the prevalence of overweight and obesity among studies and different age groups can be due to differences in sampling methods or possibly because of the actual difference in their amounts, which can be attributed to a different lifestyle due to urbanization such as reduced mobility Changes in nutrition patterns, and more. In examining the prevalence of high blood pressure in the present study, the findings suggest that hypertension (meaning a systolic blood pressure higher than $140 \mathrm{~mm} \mathrm{Hg}$ and a diastolic blood pressure higher than $90 \mathrm{~mm} \mathrm{Hg}$ ) Has not been observed in any of the students of Shahrekord University of Medical Sciences, and is also prone to hypertension, it means that systolic blood pressure is between 120 and $139 \mathrm{~mm} \mathrm{Hg}$ and diastolic blood pressure is between 80 and $90 \mathrm{~mm} \mathrm{Hg}$, and 3.5\% among students. Meanwhile, there is a positive and significant correlation between body mass index and hypertension in the present study. In a study of Rahmati among university students in Tehran, it was found that $2.7 \%$ of students had elevated systolic blood pressure of 140 and $4.8 \%$ with elevated diastolic blood pressure (90 and above), and a significant correlation was found between blood pressure and weight gain (2), in the study of Salem in Rafsanjan university of Medical Sciences also found that $27.4 \%$ of the students had abnormal systolic blood pressure (above $120 \mathrm{mmHg}$ ) and 28\% had abnormal diastolic blood pressure (above $90 \mathrm{mmHg}$ ) and a significant relationship between BMI and There is an increase in blood pressure (1).

A remarkable point in the two recent studies and its comparison with the present study is that in previous studies, high blood pressure and high blood pressure have not been studied separately. In a Salem study, hypertension was generally higher than 120 and diastolic blood pressure above 80 was associated with hypertension Abnormalities have been considered, while in present study these two parameters, hypertension and high blood pressure have been studied separately. In the study of Rahmati, only high blood pressure has been studied and the pre-hypertensive outbreak has not been studied and these two studies Therefore, they are different from the present study. Another variation of the present study with previous studies is that in the present study, the left and right hand blood pressure was measured separately in two steps and the second-order blood pressure in both hands was related to parameters such as age, sex, Body mass index and other measured parameters have been analyzed statistically. It should be noted, however the blood pressure of both hands is almost intimately, and the results are almost the same as in other parameters. Also, in a study conducted in Kuwait on students aged 6 -10 years, the overall prevalence of hypertension was $5.1 \%$ and obese children were more likely to have it, and there was a significant relationship between obesity and hypertension (10). Also, in the study of Fesharaki nia et al., $4.5 \%$ obesity and $8.1 \%$ of abnormal blood pressure have been observed and confirms the direct relationship between high blood pressure and obesity (7). Khaji Studies also confirms this direct and significant relationship (8).

In general, obesity, overweight and diabetes are one of the main problems in today's world, that an inappropriate combination (low physical activity and unhealthy foods) leading to an uncontrollable increase in the prevalence of obesity and diabetes in the world (17-21).

In the study of Abbasian, which studies the complications of diabetes in diabetic patients, it is evident that with an increase in BMI, heart disease has increased prevalence, which causes problems such as blood pressure and other complications (22). 


\section{Conclusion}

In general, the present study confirms the relationship between BMI, blood pressure and age, and the result is consistent with many other studies.

\section{Thanks and appreciation}

This article is a result of a research project approved by Shahrekord University of Medical Sciences which was registered at Shahrekord University of Medical Sciences Research and Technology Dept. No91-01-83-1511. We are grateful to the Student Research Committee of Shahrekord University of Medical Sciences and all those who helped us with this study.

\section{Conflict of interest}

There are no conflicts of interest in this study.

\section{References:}

1. Janssen, I., Bacon, E. and Pickett, W., 2011. Obesity and Its Relationship with Occupational Injury in the Canadian Workforce. Journal of Obesity, Article ID 531403, P. 6.

2. Barzin, M., Hosseinpanah, F. and Arzhan, S.F.A., 2011.Trends of obesity and abdominal obesity in Tehranian adults (1999-2008). Pejouhandeh, 16, pp. 212-228.

3. Who, 2010. Chronic diseases are the major cause of death and disability worldwide. [Cited 2010 Aug 12]; Available from: http:// www. Who. int/ chp/ choronic_disease report/ media/ Factsheetl.pdf

4. Azizi A, Abasi MR, Abdoli GR. The prevalence of Hypertension and its Association with Age, Sex and BMI in a Population Being Educated Using Community-Based Medicine in Kermanshah: 2003. Iran J Endocrinol Metab 2008; 10(4): 323-30. [In Persian].

5. Kearney PM, Whelton M, Reynolds K, Whelton PK, He J. Worldwide prevalence of hypertension: a systematic review. J Hypertens 2004; 22(1): 11-9.

6. Azizi F, Hatami H, Jonghorbani M. Epidemiology and control disease in Iran. Tehran: Eshtiagh Publication .2010; [In Persian].

7. Salem z, Rezaeian M, Blood pressure status and its association with obesity and abdominal obesity instudents of rafsanjan university of medical sciences, J Rafsanjan Univ med Sci. 2007, 3(7): 157-164

8. Rahmati f, MoghadasTabrizi Y, Shidfar F, Habibi F, Jafaray MR. Prevalence of obesity and hypertension among Tehran university students. Payesh, 2004, 2(3): 123-30

9. Kristjansson K, Sigurdsson JA, Lissner L, Sundh V, Bengtsson C. Blood pressure and pulse pressure development in a population sample of women with special reference to basal body mass and distribution of body fat and their changes during 24 years. Int $J$ ObesRelatMetabDisord 2003; 27(1): 128-33

10. Paknahad Z, Saboktagin M, Studying the blood pressure in Isfahan rural residents and itsrelationship with BMI. J Health System Research, 2010, 3 (6): 506-512
11. Ziaee V, Fallah J, Rezaee M, Bita A, The relationship between body mass index and physical fitness in 513 medical students, J Tehran Univ med Sci, 2007, 8(65): 7984

12. Khosravi AR, AkhavanTabib A, Golshadi I, Dana Siadat Z, Bahonar A, Zarfeshani S, Alikhasi H, Rezaee SH, Noori F, Hashemi SM, The Relationship between Weight and CVD Risk Factors in a Sample Population of Central Part of Iran (Based on IHHP). J Isfahan Univ med Sci, 2010, 17(72): 31 $-41$

13. Fesharaki A, Taheri F, Saadatjou AR, The relationship between body mass index and blood pressure among children (7-11) in Birjand, Iran. J BirjandUniv med Sci, 2001, 1(8): 39-41

14. Khaje A et al, Blood pressure and obesity in adolescents in Tehran. Journal of Children's Diseases, 2008,1(16): 50-54

15. Mortazavi Z, Shahrakipoor M, body mass index in Zahedan University of medical sciences student. Tabibe shargh2002, 2(4):81-86

16. Sorof J, Daniel S, obesity hypertension in children: a problem of epidemic proportion 2002; oct, 40(4): 441-7

17. Moslemirad M, Madmoli M, Madmoli Y, Niksefat M. Prevalence of type 1 and type 2 diabetes and its related factors in diabetic patients hospitalized in Khatam-ol-Anbia hospital in Shoushtar, 2014-15: A retrospective study. Journal of Research in Medical and Dental Science. 2018;6 (3):421-6

18. Madmoli M, Eilami O, Rezaie K, Aliabad MA, Moslemirad M. Diabetes and the risk of suffering cardiovascular Diseases: A two-year retrospective study. International Journal of Ecosystems and Ecology Science (IJEES). 2018 Jun;8(3): 649-56.

19. Madmoli M Rostami F, Mirsami Yazdi N, Mosavi A, Baraz Sh. Evaluation of Prevalence of Diabetic Foot Ulcer and Its Related Factors in Diabetic Patients Admitted to KHatam-ol-Anbia Hospital in Shoushtar During 20152016: A Retrospective Study. International Journal of Ecosystems and Ecology Science (IJEES). 2018 June; 8 (3): 545-52.

20. Rostami F, Madmoli M, Mirsami Yazdi N, Baraz Sh. Evaluation of The Prevalence of Lower Limb Amputation and Its Related Factors in Diabetic Patients Admitted to KHatam-ol-Anbia Hospital in Shoushtar During The 20152016: A Retrospective Study. International Journal of Ecosystems and Ecology Science (IJEES). 2018 June; 8 (3): 553-60.

21. Raisifar Z, Afshar Nia A, Madmoli M, Madmoli Y. The Relationship Between Using Insulin and Suffering Alzheimer's Disease in Patients with Diabetes: A Two-Year Study. International Journal of Ecosystems and Ecology Science (IJEES). 2018 June; 8 (3): 623-28.

22. Abbasian M, Delvarian-Zadeh M. Evaluation of diabetes complications among the diabetic patients visiting the Shahroud diabetic. Knowledge \& Health Journal 2008;10 (4):16-20. 